\title{
Christian Baechler, Clergé catholique et politique en Alsace 1871-1940
}

Strasbourg, Presses universitaires de Strasbourg, 2013, 252 p.

Jean-Louis Ormières

\section{OpenEdition}

\section{Journals}

Édition électronique

URL : http://journals.openedition.org/assr/26284

DOI : $10.4000 /$ assr.26284

ISSN : $1777-5825$

Éditeur

Éditions de l'EHESS

Édition imprimée

Date de publication : 31 décembre 2014

Pagination : 116

ISBN : 978-2-7132-2467-6

ISSN : 0335-5985

Référence électronique

Jean-Louis Ormières, "Christian Baechler, Clergé catholique et politique en Alsace 1871-1940",

Archives de sciences sociales des religions [En ligne], 168 | 2014, mis en ligne le 31 mars 2015, consulté le 22 septembre 2020. URL : http://journals.openedition.org/assr/26284 ; DOI : https://doi.org/

10.4000 /assr.26284

Ce document a été généré automatiquement le 22 septembre 2020

(c) Archives de sciences sociales des religions 


\section{Christian Baechler, Clergé} catholique et politique en Alsace 1871-1940

Strasbourg, Presses universitaires de Strasbourg, 2013, 252 p.

Jean-Louis Ormières

\section{RÉFÉRENCE}

Christian Baechler, Clergé catholique et politique en Alsace 1871-1940, Strasbourg, Presses universitaires de Strasbourg, 2013, 252 p. 
1 Auteur de plusieurs ouvrages sur l'Allemagne et sur l'Alsace, C. Baechler analyse le lien qui unit et désunit religion et politique entre la chute de l'Empire et celle de la Troisième république.

Dans un premier chapitre, il entend rendre compte d'une particularité de l'Alsace sur ce plan. Alors que dans la plupart des régions françaises bon nombre d'ecclésiastiques sollicitent le suffrage des électeurs lors de l'instauration du suffrage universel, en 1848, rien de tel en Alsace. Cependant, en 1874, lors des premières élections au Reichstag, 6 des 11 élus alsaciens appartiennent au clergé. La cause majeure de cet engagement est celle de la défaite de 1870 qui avait abouti à l'annexion de l'Alsace et de la Lorraine par un Empire

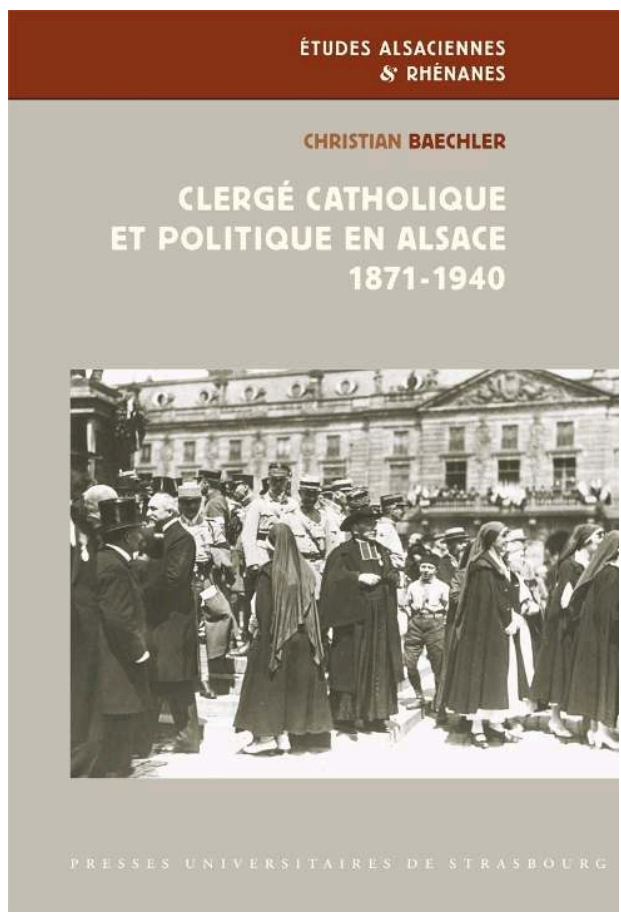
allemand dominé par la Prusse protestante. Source de menace pour la position de l'Église, une telle situation incite nombre de clercs à entrer dans l'arène politique pour défendre les institutions religieuses d'autant qu'une partie des élites laïques a fait le choix de l'émigration. Cet engagement s'inscrit également dans un contexte général de sécularisation progressive de la société. Enfin, le contenu des encycliques de Léon XIII ne peut qu'encourager le clergé, par ailleurs en expansion, à intervenir dans la vie politique et sociale.

3 À l'inverse, le reflux progressif du clergé de la vie politique alsacienne après 1918 s'explique principalement par la réintégration de la région dans une France anticléricale, par une démographie cléricale en déclin compensée par l'émergence d'une élite laïque formée susceptible de prendre la relève dans le domaine de la vie associative, syndicale et politique.

4 La question sociale et la réception de l'encyclique Rerum Novarum par les catholiques alsaciens font l'objet d'un second chapitre. L'auteur souligne que si l'encyclique n'entraîne aucun changement profond d'orientation du catholicisme politique et social alsacien, elle encourage néanmoins le clergé à l'action sociale et politique. Désireux de reconquérir la société alsacienne au christianisme, le clergé multiplie les initiatives dans le domaine religieux, politique et social. Il s'en suit un essor continu des cercles catholiques et le développement d'un puissant syndicalisme chrétien.

Les quatre chapitres consacrés à de fortes personnalités du clergé alsacien témoignent de la vigueur de cet engagement clérical au lendemain de l'annexion.

Nicolas Delsor (1847-1927), prêtre patriote, redoutable polémiste, rejoint le mouvement protestataire qui lutte contre la domination allemande avant de rentrer au Parti catholique alsacien, dont il devint l'un des principaux leaders, et entre au Reichstag. Très attaché à l'école confessionnelle qu'il juge indispensable à la préservation de la société chrétienne en Alsace, il milite pour la restauration de la liberté de l'enseignement. Plus jeune, Émile Wetterlé (1861-1931), non moins patriote, partage 
avec son aîné une même conception «libérale » de la démocratie chrétienne. Soucieux de restaurer la liberté de l'enseignement Wetterlé n'est cependant pas hostile à l'école publique laïque. L'un et l'autre envisagent sans trop de crainte l'éventualité d'une séparation de l'Église et de l'État, mais devant la montée de l'anticléricalisme Delsor la jugera nuisible.

7 Défenseur impénitent d'une Alsace catholique, germanophile, l'abbé Xavier Haegy représente aux yeux des anticléricaux le cléricalisme le plus obtus. Partisan d'une démocratie "populaire ", hostile aux notables, il se prononce pour un parti catholique de masse. Lors du débat sur la constitution de 1911, il se prononce pour une AlsaceLorraine autonome et approuve ceux qui préconisent la constitution d'un parti national alsacien-lorrain. De tous les ecclésiastiques, il est sans conteste celui qui appelle avec le plus d'insistance le clergé à sortir de la sacristie pour se mêler aux luttes politiques. L'amalgame entre le politique et le religieux est nécessaire à ses yeux pour "réinsuffler un esprit chrétien dans la société et l'État. » Proche de l'abbé Haegy, mais plus souple, comme en témoigne son adaptation au contexte de l'État laïque français après 1918, Eugène Muller (1861-1948) n'en est pas moins favorable lui aussi à l'amalgame entre la cause du peuple et la cause de l'Église et milite pour une démocratie chrétienne cléricale et non libérale. Membre du Reichstag en 1906, ce n'est qu'après 1918 qu'il exerce un réel « magistère moral ».

8 Tout en rendant bien compte de la diversité du clergé alsacien, durant la période de l'annexion comme après, ces quatre biographies offrent une réelle illustration de la vigueur de son engagement dans la vie religieuse politique et sociale de la région. 